\title{
A RISK BASED METHODOLOGY TO ASSESS THE ENERGY EFFICIENCY IMPROVEMENTS IN TRADITIONALLY CONSTRUCTED BUILDINGS
}

\author{
D. Herrera ${ }^{\text {a, } *, ~ A . ~ B e n n a d j i ~}{ }^{\text {a }}$ \\ ${ }^{a}$ Scott Sutherland School of Architecture and Built Environment, Faculty of Design and Technology. The Robert \\ Gordon University, Aberdeen, United Kingdom \\ d.herrera-gutierrez-avellanosa@rgu.ac.uk \\ a.bennadji@rgu.ac.uk
}

KEY WORDS: traditional building, energy efficiency, retrofit, thermal insulation, risk assessment, building survey

\begin{abstract}
:
In order to achieve the $\mathrm{CO}_{2}$ reduction targets set by the Scottish government, it will be necessary to improve the energy efficiency of existing buildings. Within the total Scottish building stock, historic and traditionally constructed buildings are an important proportion, in the order of $19 \%$ (Curtis, 2010), and represent cultural, emotional and identity values that should be protected.

However, retrofit interventions could be a complex operation because of the several aspects that are involved in the hygrothermal performance of traditional buildings. Moreover, all these factors interact with each other and therefore need to be analysed as a whole. Upgrading the envelope of traditional buildings may produce severe changes to the moisture migration leading to superficial or interstitial condensation and thus fabric decay and mould growth. Retrofit projects carried out in the past have failed because of the misunderstanding, or the lack of expert prediction, of the potential consequences associated to the envelope's alteration.

The evaluation of potential risks, prior to any alteration on building's physics in order to improve its energy efficiency, is critical to avoid future damage on the wall's performance or occupants' health and well being. The aim of this $\mathrm{PhD}$ research project is to point out the most critical aspects related to the energy efficiency improvement of traditional buildings and to develop a risk based methodology that helps owners and practitioners during the decision making process.
\end{abstract}

\section{INTRODUCTION}

Climate change is one of the most important current challenges of our society. Governments all over the world are developing new regulations to reduce our green house gases emissions and energy consumption. In Scotland, for instance, according to the Climate Change (Scotland) Act 2009, total carbon emissions should be reduced $42 \%$ by 2020 respect 1990 levels (and $80 \%$ lower than the baseline by 2050).

In this context, it is important to highlight that buildings are responsible of $45 \%$ of total $\mathrm{CO}_{2}$ emissions (RAENG, 2010) and just residential buildings represent $26 \%$ of $\mathrm{UK} \mathrm{CO}_{2}$ emissions (Moran, Nikolopoulou \& Natarajan, 2012). Moreover, due to the low average renovation rate in Europe, $1.2-1.4 \%$ per year (Dyrbøl, Thomsen \& Albæk, 2010), it is estimated that between $80 \%$ (RAENG, 2010) and 85\% (Palmer et al., 2006) of the buildings we will occupy by 2050 are already built. Therefore, to achieve the established $\mathrm{CO}_{2}$ reduction objectives, it will be necessary to improve the energy performance of the current building stock.

On the other hand, the importance of traditional and vernacular architecture is recognized in the Charter on the Built Vernacular Heritage elaborated by the International Council on Monuments and Sites in 1999. In this charter, the principles for conservation and guidelines for practice were established.

\footnotetext{
"Adaptation and reuse of vernacular structures should be carried out in a manner which will respect the integrity of the structure, its character and form while being compatible with acceptable standards of living" (ICOMOS, 1999).
}

Nowadays, buildings built before the World War II have become part of the focus of the retrofit programmes in Scotland because of the great amount of energy that these buildings need to spend to achieve the current standards of comfort.

However, there is a risk that government grant's announcements could lead home owners to carry out thermal refurbishment works without taking into account the potential risks related to these interventions. In previous occasions, the lack of information during the decision making process caused the choice of wrong insulation materials and, as a result, the apparition of condensation, dampness and mould (Bennadji, Scott \& Taylor, 2009).

Development of a risk based methodology could simplify the decision making process, allowing the optimal energy efficiency improvement of traditional buildings by establishing the most appropriate retrofit strategies in each particular case.

\subsection{Traditional building definition}

As defined by Historic Scotland, a historic building is:

"A building of architectural or historic interest or significance. The interest or significance may be local or national, and may be a consequence of, for example, the building's age, built form or location. It may result from its connection with a person or persons, or with local or national events or industry; or from a combination of these or other factors. A building does not have to be listed by Scottish Ministers or lie within a conservation area to have interest or significance" (Urquhart, 2007).

\footnotetext{
* Corresponding author.
} 
Therefore, in this case it will be necessary to take into account not only listed buildings, but all traditionally constructed buildings. The term traditional is applicable to:

- "Buildings built using load-bearing mass masonry walls, with pitched roofs covered in slate or another natural roofing material" (Historic Scotland, 2012)

- "Construction with permeable fabric that both absorbs and readily allows the evaporation of moisture" (Wood, Brocklebank \& Pickles, 2010)

In line with these definitions, in this paper, traditional buildings will be defined as those built using permeable load-bearing mass masonry walls with pitched roofs. In Scotland, these are the characteristics of the majority of buildings built before 1919 and most of those built until 1945.

\subsection{Research objectives}

The aim of this research is to develop a model that allows the identification of the optimal levels of energy efficiency that can be achieved in traditional buildings through the refurbishment of its envelope without endanger the preservation of the built heritage or occupants' health. The specific objectives established to achieve this goal are:

- To develop a method for surveying traditional buildings in order to document the current state of the construction and to identify the potential for upgrading

- To identify the main risks to the fabric conservation, human health and cost feasibility associated to the traditional buildings' retrofit.

- To assess the extent to which traditional buildings are at risk due to inadequate energy retrofits.

- To propose effective strategies for the refurbishment of solid masonry dwellings in Scotland based upon a risk assessment model

\section{TRADITIONAL BUILDINGS PERFORMANCE}

Before the implementation of any retrofit measure it is necessary to understand the hygrothermal behaviour of traditional buildings and the existing differences between traditional and modern construction (fig. 1).

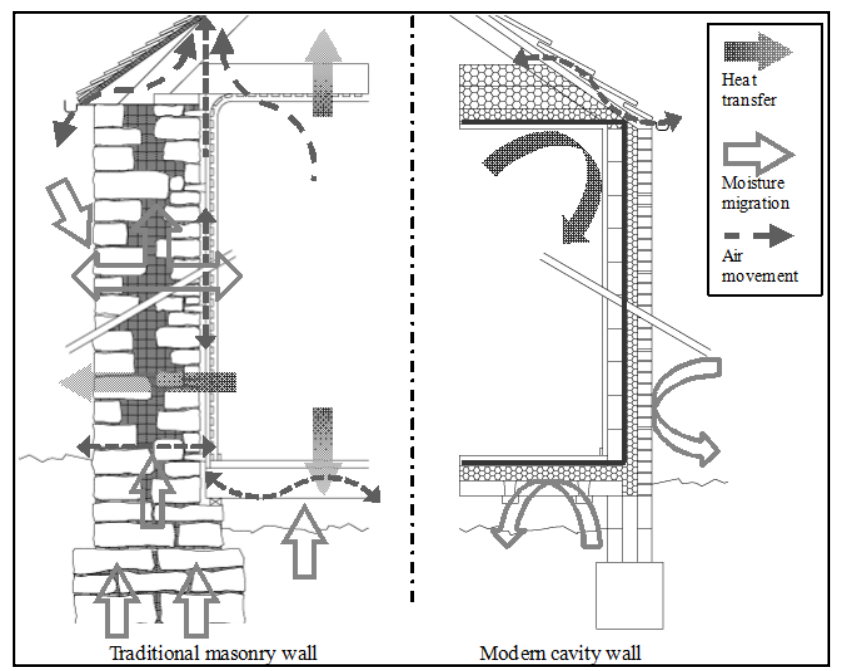

Figure 1. Traditional vs. Modern construction.
Upgrading the thermal performance of traditional buildings' envelope and reducing the air leakage shall produce changes in the indoor environment. These changes may be associated with risks of superficial and interstitial condensation which may lead to fabric decay or mould growth.

The lack of relevant research in some aspects of traditional building physics may produce misunderstandings on the behaviour of these buildings and, as a result, some unintended consequences could appear after the thermal retrofit (STBA, 2012).

\subsection{Heat loss}

As described above, Scottish buildings are traditionally built using solid masonry walls, pitched slate roofs and timber sash and case windows. It is well known that traditional materials used in these constructions have a poor thermal performance compared to current insulation materials. However, there are some difficulties to model the energy performance of traditional buildings due to the lack of information of traditional materials and the discrepancy between the data obtained through the simulation software and the in-situ calculations (Baker, 2011).

According to recent publications, in-situ measurements of traditional walls have showed better U-values than default values, in part because of the underestimation of lime mortar influence on the thermal transmission.

\subsection{Moisture migration}

Traditional buildings deal with moisture in a completely different way that modern construction (fig. 1). While current buildings try to keep humidity out of the envelope using impermeable barriers, traditional construction uses the porosity and permeability of natural materials to buffer and slowly evaporate the moisture (Urquhart, 2007).

Types and characteristics of materials used in construction vary in each region and, therefore, the building performance will also vary depending on the chosen materials.

Changes on the hygrothermal characteristics of the envelope's layers due to internal insulation or inappropriate repointing could lead to interstitial condensation and thus deterioration of the internal lath and plaster, fabric decay or even structural failure due to the degradation of timber joists ends (May, 2005).

\subsection{Air permeability}

To control internal moisture presence, traditional construction relies on air renovation in order to avoid condensation and mould growth. Ventilation is usually achieved by uncontrolled air leakage and, therefore, it is not suitable to be adjusted depending on the external conditions or the indoor air quality.

However, there is again an important disparity between expected and measured results in traditional buildings. The "rule of thumb" of ventilation, that used to say that traditional buildings had twice the normal levels of ventilation, has been proved to be not always truth (Hubbard, 2011).

Besides the effects that may have on the fabric conservation, dampness and inadequate ventilation are the main factors for the presence of biological agents associated to occupants' health problems (Afshari et al., 2009). 


\subsection{Documenting traditional buildings' performance}

For a better understanding of the building's performance and to have a record of its current condition, a complete survey might be carried out before commencing any decision making process.

As suggested by ICOMOS in its Guide to recording historic buildings, "records are needed in planning a maintenance programme, in monitoring the long-term effects of repair and remedial works, in identifying defects that may appear over time or in deciding whether any historical aspects of the building call for specially careful treatment" (ICOMOS, 1990).

To carry out a complete survey will help to comprehend and illustrate the building's characteristics and evolution throughout its history. Detailed records of plans, structure, materials or changes in the use should be taken into account when defining the energy efficiency measures to be applied. In addition to that, practitioners must elaborate an exhaustive documentation regarding the elements that are to be preserved, restored or replaced.

A detailed survey might be time consuming and it is acknowledged that practitioners may not have time to undertake it (Thomson, 2000). However, an inadequate examination of the building's performance could lead to a misunderstanding of the refurbishment's effects and thus the appearance of unintended consequences. For that reason, might be necessary to develop a template that helps practitioners to gather all the relevant information related to the building and the site conditions prior to any refurbishment work.

\section{ENERGY EFFICIENCY MEASURES}

An upgrade measure may be described as: "an action that seeks the improvement of a building in terms of energy use and thus associated $\mathrm{CO}_{2}$ emissions" (STBA, 2012).

Some of the main characteristics of traditional construction make these buildings be considered as "hard-to-treat". Conventional measures, like cavity wall insulation, loft insulation or air tightness, are not always possible to apply. Moreover, beyond the technical difficulties, the inherent characteristics of heritage buildings require specific approaches in each particular case (Rohdin, 2011).

\subsection{Thermal insulation}

Thermal improvement of traditional buildings is conditioned by the physical characteristics of each specific building. As mention before, most of traditionally constructed Scottish buildings have solid walls with ashlar facing, so external insulation would be inappropriate in most of the cases. Internal insulation feasibility shall depend on the existing finishes. Traditional walls were usually built with internal lath and plaster to allow the air movement and avoid the condensation. To preserve the original character, if the original lining is in good condition, internal insulation should be avoided and the possibility of cavity insulation studied (Bennadji \& AbdelWahab, 2012).

Most appropriate system for floor insulation will depend on the existing typology. Suspended timber floors could allow insulation between joists while solid slab floor will require lifting the original finishes and excavating to a new level.
Pitched roof insulation will vary depending on the use of the roof space. In houses with ventilated roof space, the insulation could be placed at ceiling level, meanwhile in buildings where rooms are provided within the roof space the insulation should be placed between the rafters.

Windows and doors could be improved by replacing it (with the inherent change on the building's character) or by adding secondary glazing, shutters, blinds or insulating panels.

Insulation thickness. The optimal insulation thickness will depend on the practical and effective limits imposed by the characteristics of the building.

- Typology construction. Building characteristics will restrict the reachable insulation levels. As described before, external insulation will destroy the character of the building and the internal insulation will depend on the existence of the original features like lath and plaster, cornices, panelling or shutters.

- Thermal bridges. There are several thermal bridges in traditional buildings that are very challenging to solve during the thermal retrofit (windows ingoes, wall-to-floor junctions, etc). The risk of condensation in these areas raise greatly with the envelope's insulation because of the higher vapour pressures and the appearance of cold spots. Moreover, due to the heat loss trough the unavoidable thermal bridges existing in traditional construction, there are effective limits for the internal insulation. In short, any internal insulation beyond the optimal level will only lead to increase the condensation risk and decrease the marginal returns.

\subsection{Air tightness}

The other main factor that affects the heat losses in buildings is the envelope's air tightness. The high rate of uncontrolled air leakage of traditional buildings makes them more difficult to heat than modern buildings where the adequate levels of ventilation are adjusted with passive or mechanical systems.

By reducing the air leakage in traditional constructions, the amount of air that needs to be heated is directly reduced. However, as discussed before, it is necessary to allow an adequate rate of air renovation to avoid the risk of superficial condensation and mould growth. Air tightness could be improved by draught proofing doors and windows, sealing chimney flues or by wall and roof insulation.

Air renovation levels. Adequate air renovation rates are crucial to ensure the preservation of traditional fabrics but also the indoor environmental quality. Ventilation shall remove or dilute pollutants and control the internal humidity.

- Indoor Air Quality. Air renovation should guarantee the achievement of adequate levels of indoor air quality. The World Health Organisation links the presence of many biological agents in the indoor environment with the presence of dampness and inadequate ventilation (Afshari et al., 2009). According to the WHO, "as exact values for ventilation cannot be identified and limit values have not been set for all pollutants, it is seldom possible to determine the necessary ventilation rates and the associated risks on the basis of pollutant concentrations". However, organisations like ASHRAE (2001) make recommendations of ventilation rates for "acceptable indoor air quality" $(0.35$ air changes per hour or $7.5 \mathrm{l} / \mathrm{s}$ per person in residential living areas). 
- Weather conditions. External climatic conditions and building's exposure will affect directly the effects of air renovation. In humid places, for instance, high rates of natural ventilation could lead into a greater humidity and thus a higher risk of condensation and mould formation.

Available databases usually only show generic data for large regions, while for an accurate evaluation of optimal air renovation rates it would be necessary to collect site-specific weather data and information about the location and orientation of the retrofitted building.

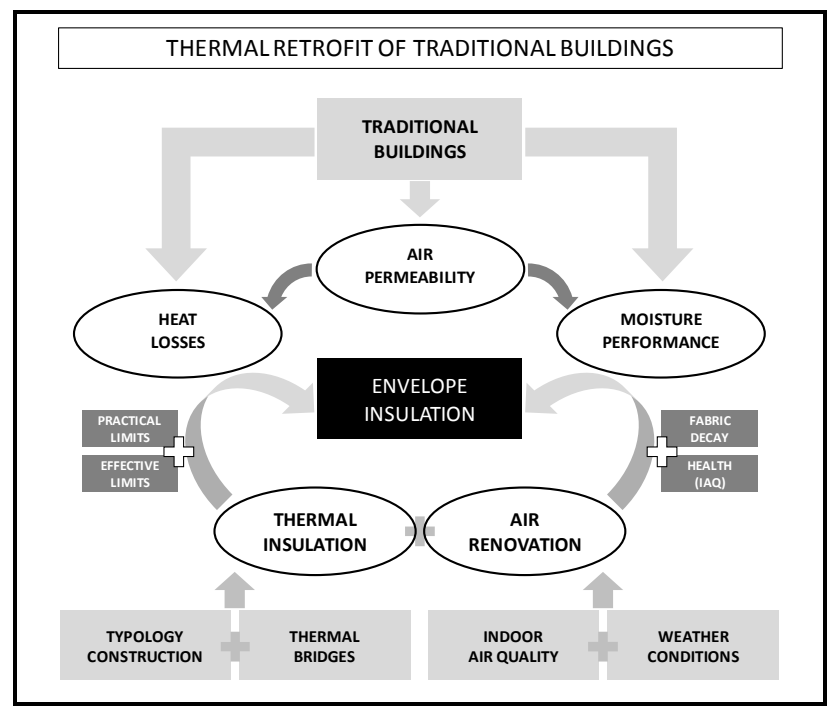

Figure 2. Parameters involved in the thermal retrofit of traditional buildings

There are several factors involved in the thermal retrofit of traditional buildings that may affect the final result (fig. 2). To avoid any potential risk and to ensure the best energy performance it is necessary to develop a methodology that helps during the decision making process by gathering and evaluating all these aspects.

\subsection{Documenting post occupancy building's performance}

Most of the current regulation focused on the reduction of the energy use relies on predictive calculation. However, there is an increasing concern due to the disparity between expected and measured results (Tuohy, 2012). This deviation may be even greater when improving traditional buildings, due to the lack of accuracy of the traditional materials performance modelling.

Evaluation of post occupancy building's performance will help decision makers to realise to which extent their plans have been successful (Maclennan, 1991). Furthermore, understanding of the results of these evaluations should be the base for future plans and policies. Having replicable measurements for the evaluation of the degree of success of retrofit works will increase the knowledge of the end results and thus reinforce the decision making process.

Two main methods may be used in post occupancy evaluations, energy auditing and user perception surveys. First one includes the monitoring of energy consumption, temperatures and humidity levels, while the users approach is useful for describing the occupants' perceptions and experiences of the indoor environment and can be an effective way to evaluate the results of measures (Rohdin, 2011).

\section{INTEGRATED RISK ASSESSMENT}

Although the carbon emissions reduction target is established and governments are encouraging practitioners and owners to upgrade the thermal performance of the existing building stock, there are no specific guidelines or generic hierarchy of interventions to improve historic and traditional buildings.

As the STBA summarises in a recent publication: "there is a strong need to develop an open and iterative guidance tool which lays out risks and opportunities at all stages of the retrofit process and which encourages a systemic and learningbased approach at all levels including policy" (STBA, 2012).

Risk management in modern construction is usually applied to control three primary targets: cost, time and quality (Smith, Merna \& Jobling, 2009). However, this methodology could be adapted and used for the evaluation of any kind of project. In the case of traditional buildings retrofit, this method could help to identify any risk associated to the energy efficiency improvement and to exploit all the opportunities.

According to ISO 31000, risk is the "effect of uncertainty on objectives". There is, hence, a direct relationship between potential risks and the uncertainty level of the expected results.

- Risk: the term is originated in France in the XVII century and adopted by the English insurance companies around 1830. Risk could be defined as the product of the probability of occurrence of an event by the cost associated with it.

- Uncertainty: this term is used when it is not possible to quantify the probability of occurrence of an event. So, uncertainty exists when there is more than one possible outcome but the probability of each one is not known.

Risks can be ranked using an assessment scale (fig. 3). A hierarchy classification of risks might help to clearly identify the most critical threats associated to the refurbishment projects.

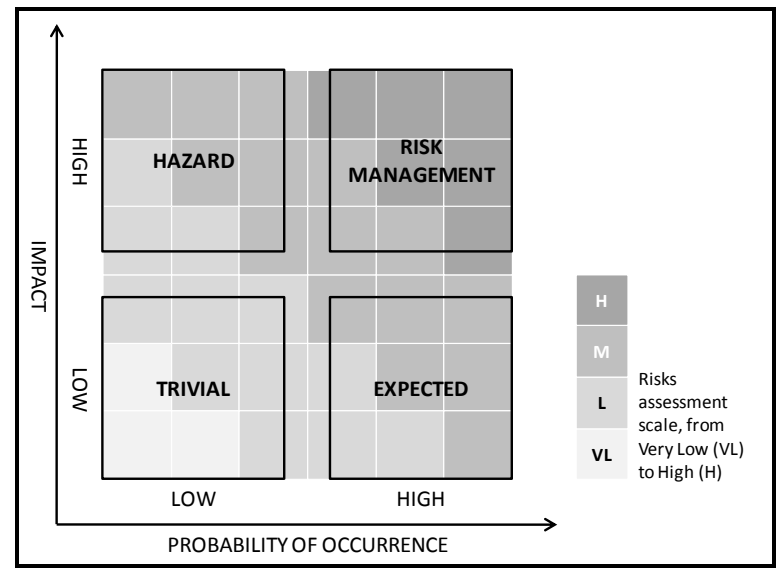

Figure 3. Hierarchy and classification of risks. Adapted from (Smith, Merna \& Jobling, 2009)

Risk assessment could be used as a decision making tool to identify and prioritize the possible unintended consequences and missed opportunities for energy efficiency improvement.

\subsection{Risk categories}

Risks, and opportunities, associated to the retrofit of traditional buildings could be gathered into three different groups: heritage preservation, occupants' health and energy demand. 
Heritage preservation. Traditional buildings form a valuable heritage for the Scottish culture and economy (Galbraith et al., 2009). Thus, it is crucial that thermal retrofit measures could guarantee the preservation of this built heritage by avoiding any possible risk that may endanger the existing buildings.

Most common risks associated to traditional buildings' retrofit are the loss of original features, because of the application of internal insulation or the substitution for new ones more efficient, and the fabric decay due to the interstitial condensation in walls, floor or roof.

Healthy environment. It has been established the relationship between indoor air quality and occupants' health. However, for retrofitted traditional buildings, the existing research on indoor environmental quality in highly energy-efficient buildings is really limited (Hobday, 2011).

It is well known that buildings with high levels of internal humidity could lead to increased risk of respiratory diseases and the exacerbation of asthma. Therefore, it is important to ensure that air tightness measures focussed on the energy demand reduction do not increase the internal humidity levels and with that the risk for human health.

Energy demand reduction. $\mathrm{CO}_{2}$ emissions and energy costs reduction is the main goal of energy efficiency measures. Therefore, the risk assessment should help to find the optimal level of improvement that ensures the cost effectiveness of the intervention and that the use of new materials will not produce an environmental impact greater that the current situation (Herrera \& Bedoya, 2012).

Traditional buildings upgrading might be limited by thermal bridges and other inherent characteristics of these constructions. As discussed before, greater levels of insulation or air tightness could only lead to larger payback periods due to the unavoidable heat losses.

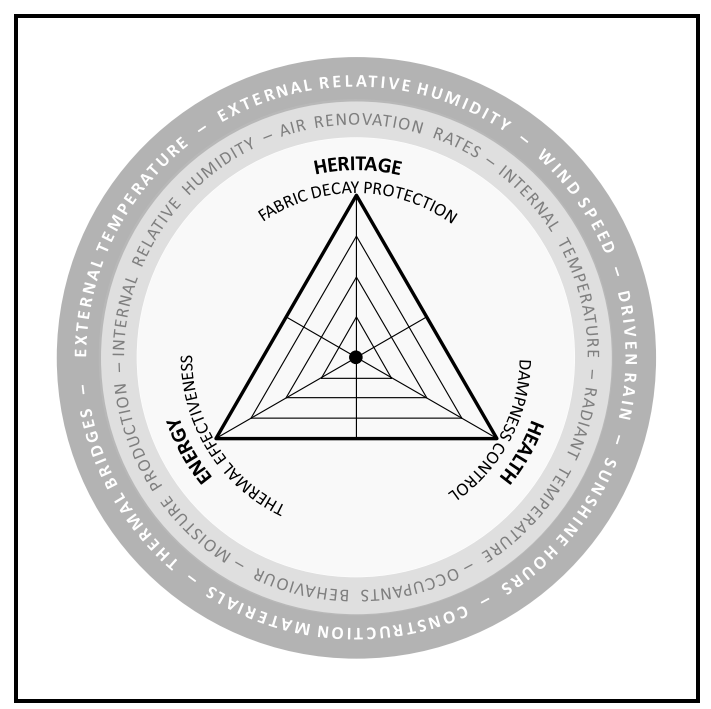

Figure 4. Traditional buildings' thermal retrofit risk assessment categories.

All mentioned aspects are conditioned by the effects of the refurbishment works (changes on the temperature and humidity levels), but also by the pre-existing or external circumstances (climatic conditions or construction typologies) (fig. 4).
Therefore, to assess the risk associated to the energy efficiency improvement of traditional buildings is crucial to include the analysis of the existing buildings and the local climate.

\subsection{Methodology}

Following, the main steps of the methodology are described.

Building and site survey. For an adequate assessment of the intervention it is crucial to carry out a comprehensive documentation of the current situation of the building and the main characteristics of the site.

Firstly, specific climatic data should be collected in each particular case for an accurate evaluation. This information must include data for temperature, humidity, wind, wind-driven rain and sunshine hours.

Detailed information of the characteristics of the existing building is crucial for the feasibility and risk assessment of the retrofit measures. The survey should include the building's location and orientation, construction system and materials, potential thermal bridges and internal (and external) finishes

Proposed retrofit measures. Once the weather conditions are established and the existing building's survey completed it is time to choose among the possible retrofit options. Energy efficiency measures shall be focussed on the thermal performance and uncontrolled air leakage of the envelope.

Risk matrix. Once the risks associated to the refurbishment are identified, the risk matrix establishes a hierarchy based on probability and impact. The risk critical index (table 1) is established by defining the probability of these risks might happen and the impact they might produce in each selected category.

\begin{tabular}{|c|c|c|c|c|c|c|c|c|c|c|}
\hline \multicolumn{3}{|c|}{ RISKS } & \multicolumn{8}{|c|}{ ASSESSMENT } \\
\hline \multirow[b]{2}{*}{$\dot{\theta}$} & \multirow{2}{*}{ 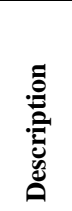 } & \multirow[b]{2}{*}{ 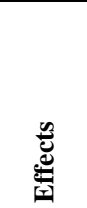 } & \multirow[b]{2}{*}{ 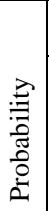 } & \multicolumn{3}{|c|}{ Impact index } & \multicolumn{3}{|c|}{ Critical index } & \multirow{2}{*}{ 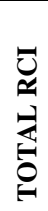 } \\
\hline & & & & 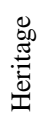 & 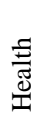 & $\begin{array}{l}\text { के } \\
\text { Dे } \\
\text { ज्ञ }\end{array}$ & 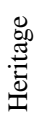 & 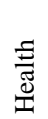 & 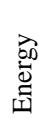 & \\
\hline 1 & Risk & Effect & 3 & 1 & 2 & 3 & 3 & 6 & 9 & 18 \\
\hline 2 & Risk & Effect & 2 & 1 & 2 & 3 & 2 & 4 & 6 & 12 \\
\hline 3 & Risk & Effect & 1 & 1 & 2 & 3 & 1 & 2 & 3 & 6 \\
\hline
\end{tabular}

Table 1. Risk matrix

Risk response. To prevent the effects of the detected risks shall be necessary to establish the adequate levels of insulation and ventilation for each specific case.

To choose the optimal insulation is necessary to pay attention to both thickness and material's characteristics. The amount of insulation will define the cost effectiveness of the intervention, while the characteristics of the selected material will have a crucial role on the risk of interstitial condensation.

An optimal level of ventilation needs to balance between the minimum air change to reduce the energy consumption and the adequate levels of humidity and pollutants that ensure fabric conservation and occupants' health. 


\section{CONCLUSIONS}

An ideal retrofit of a traditional building is intended to reach the lowest possible energy demand without endanger the conservation of the fabric or the original features and guarantying a healthy indoor environment.

Traditional building's performance is affected by several aspects that interact with each other. Any improvement of the envelope (in terms of insulation or air tightness) may produce severe changes to the moisture migration leading to superficial or interstitial condensation.

In order to avoid any risk related to these changes, it is necessary to evaluate all these factors as a whole. Risk assessment methodologies could help to identify the main weaknesses during the decision making process and, therefore, to correct any possible damage before it might happen.

For a safe determination of temperature and humidity levels in traditional buildings, it will be necessary to continue studying its hygrothermal behaviour. It is essential a better understanding of how the retrofit measures affect, especially, moisture migration within the envelope.

\section{REFERENCES}

Afshari, A., et al, 2009. "WHO guidelines for indoor air quality: dampness and mould", http://www.euro.who.int/_data/assets/ pdf_file/0017/43325/E92645.pdf (08 April 2013)

ASHRAE, 2001, "Standard 62-2001, Ventilation for Acceptable Indoor Air Quality", ASHRAE, Atlanta

Baker, P. 2011, "U - values and traditional buildings-In situ measurements and their comparisons to calculated values". Historic Scotland Technical Paper 10.

Bennadji, A. \& Abdel-Wahab, M., 2012. "Academic feasibility study: Testing of a method for insulation of masonry and lath walls in existing domestic Scottish construction", http://www.cicstart.org/ userfiles/file/ FS-24-REPORT.PDF (09 April 2013)

Bennadji, A., Scott, J. \& Taylor, B., Energy Conservation Improvement of the Existing Building Park, Constraints and Challenges. In: PLEA2009 - 26th Conference on Passive and Low Energy Architecture, Quebec City, Canada, 2009

Curtis, R., 2010. Improving Energy Efficiency in Traditional Structures: Work by Historic Scotland. Journal of Architectural Conservation, vol. 16, no. 3, pp. 7-28

Dyrbøl, S., Thomsen, K.E. \& Albæk, T., 2010, "European Directive on the Energy Performance of Buildings", 2010 ACEEE, August 2010, pp. 126-140.

Galbraith, N., et al. 2009, "Report and recommendations on the economic impact of the historic environment in Scotland", Historic Environment Advisory Council for Scotland.

Herrera, D. \& Bedoya, C., Evaluación de la rehabilitación térmica de fachadas en términos de sostenibilidad. In: $4^{\circ}$ Congreso de patología y rehabilitación de edificios, PATORREB, Santiago de Compostela, Spain, 2012.
Historic Scotland, 2012. "Fabric improvements for energy efficiency in traditional buildings". http://conservation.historicscotland.gov.uk/ (28 June 2013).

Hobday, R., 2011, "Indoor environmental quality in refurbishment". Historic Scotland Technical Paper 12.

Hubbard, D., 2011. "Ventilation, infiltration and air permeability of traditional dwellings", Journal of Architectural Conservation, vol. 17, no. 3 .

ICOMOS, 1990. Guide To Recording Historic Buildings. Butterworth Architecture, London.

ICOMOS, 1999. "Charter on the Built Vernacular Heritage". http://www.icomos.org/en/charters-and-texts (08 April 2013).

ISO 31000:2009 Risk management - Principles and guidelines.

Maclennan, P., 1991. "Post-occupancy evaluation", Facilities, 9(12), 14-15.

May, N., 2005. "Breathability: The Key to Building Performance". Natural Building Technologies. www.sustainablebuildingresource.co.uk (08 April 2013).

Moran, F., Nikolopoulou, M. \& Natarajan, S., 2012, "Developing a database of energy use of historic dwellings in Bath, UK", Energy and Buildings, vol. 55, pp. 218-226.

Palmer, J., et al, 2006, Reducing the environmental impact of housing, Environmental Change Institute, University of Oxford.

RAENG, 2010, Engineering a low carbon built environment: discipline of building engineering physics, RAENG, London.

Rohdin, P., 2011, "Using an epidemiological approach as a supporting tool for energy auditing of culturally and historically valuable buildings", Energy Efficiency in Historic Buildings, Visby, Sweden, February 9-11, 2011.

Smith, N.J., Merna, T. \& Jobling, P., 2009, Managing risk: in construction projects, Wiley-Blackwell.

STBA 2012. "Responsible Retrofit of Traditional Buildings". http://www.spab.org.uk/downloads/STBA\%20responsibleretrofit.pdf (29 Jan. 2013)

Thomson, L., 2000. Scottish market crosses: development of a risk assessment model, http://openair.rgu.ac.uk (28 June 2013)

Tuohy, P.G., Murphy, G. \& Devici, G., Lessons from post occupancy evaluation and monitoring of the $1^{\text {st }}$ Passive House Scotland. In: Passivhaus Norden Conference, Trondheim, 2012

Urquhart, D., 2007, Conversion of traditional buildings, Historic Scotland, Edinburgh.

Wood, C., Brocklebank, I. \& Pickles, D., 2010, Energy efficiency and historic buildings, English Heritage, London.

\section{ACKNOWLEDGEMENTS}

The research carried out for the elaboration of this paper is part of a $\mathrm{PhD}$ research project funded by IDEAS Research Institute. 